\title{
VARIAÇÃO ESTACIONAL DA COMPOSIÇÃO QUÍMICA- BROMATOLÓGICA, DO TEOR DE MACRONUTRIENTES MINERAIS E DA DIGESTIBILIDADE "IN VITRO" DO CAPIM ELEFANTE (Pennisetum purpureum, Schum.) VARIEDADE NAPIER *
}

\author{
Attillo O. Prospero **
}

\section{RESUMO}

Com a finalidade de estudar alguns aspectos do valor nutritivo do capim elefante (Pennisetum purpureum, Schum.) variedade Napier, procurou-se, no presente trabalho, determinar os constituintes químico-bromatológicos e 6 macronutrientes minerais (nitrogenio, fósforo, cálcio, enxofre, potássio e magnésio), assim como estimar a digestibilidade "in vitro" da matéria seca e da celulose.

A matéria seca, a proteína bruta, a fibra bruta e a cinza bruta foram determinadas pelos métodos descritos pela A.O.A.C. (1965), e a celulose pelo processo descrito por CRAMPTON e MAYNARD (1938).

Dos macronutrientes minerais estudados, o cálcio, o potássio e o magnésio foram determinados por espectrofotometria de absorção atômica, o fósforo pelo processo do vanádio-molibdato de amônio, por digestão nítrico-perclórica, e o enxofre pelo método gravimétrico do bário.

A digestibilidade "in vitro" da matéria seca e da celulose foi determinada por um período de 48 horas, utilizando-se fluido ruminal de carneiro, conforme o método descrito por CARVALHO (1967) e as modificações introduzidas por SILVEIRA (1970).

Evidenciou-se a influência da maturidade sobre os constituintes químico-bromatológicos, os macronutrientes minerais e a digestibilidade "in vitro" do capim Napier. Os teores de materia seca, de fibra bruta e de celulose se elevaram e os teores de proteína bruta e cinza bruta decresceram com a maturidade da planta. Os teores de nitrogênio, fósforo, enxofre e potássio declinaram, os teores de magnésio mostraram tendência a se elevar e os teores de cálcio apresentaram constante variação com o avançar da idade da forrageira. A digestibilidade "in vitro" da matéria seca e da celulose foi influenciada negativamente pela maturidade da planta. Foram estabelecidas correlações entre os constituintes químicobromatológicos e a digestibilidade "in vitro" e entre esta e os macronutrientes minerais.

\section{INTRODUÇÃO}

Graças às facilidades de plantio, elevada produção de massa verde e resistência ao frio e a seca, o capim elefante Napier apre-

* Resumo parcial de tese de doutoramento defendida na ESALQ, em 21/3/72. Entregue para publicação em 21/11/72.

** Departamento de Zootecnia da E.S.A. "Luiz de Queiroz", Piracicaba. 
senta-se atualmente como o de mais amplo emprego dentre as forrageiras tropicais utilizadas na suplementação das pastagens, quer como capineira ou mesmo através de ensilagem.

Em consequência, torna-se necessário que se estude o valor nutritivo daquela gramínea nos seus diversos aspectos, para que se possa explorar ao máximo a sua potencialidade.

O presente trabalho, levado a efeito no Departamento de Zootecnia da E.S.A. "Luiz de Queiroz", visou a determinação dos constituintes químico-bromatológicos, o estudo da composição mineral e a estimativa da digestibilidade "in vitro" do capim Napier, durante as várias fases de seu ciclo vegetativo.

\section{MATERIAL E MÉTODOS}

O delineamento experimental foi o de blocos ao acaso, com 3 repetições e 10 tratamentos, e as parcelas constituídas de $15 \mathrm{~m}^{2}$ ( 3 ruas com 5 metros de comprimento e 1 metro entre ruas) foram estabelecidas numa gleba de solo caracterizado como Latosol Vermelho-escuro-orto.

O plantio do capim foi realizado em $26 / 11 / 67$, o primeiro corte aos 45 dias do plantio, e os demais, cada 30 dias, isto é, aos 75,105 , $135,165,195,225,255,285$ e 315 dias de idade.

As amostras coletadas eram representadas por 12 colmos da forrageira, sendo 4 dos mais desenvolvidos quanto à altura, 4 de porte médio e 4 de tamanho pequeno, cortados cerca de $5 \mathrm{~cm}$. do solo.

Os constituintes químico-bromatológicos foram determinados segundo os métodos descritos pela "Association of Official Agricultural Chemists" (A.O.A.C., 1965), a proteina bruta através da determinação do nitrogênio total pelo método de Kjeldahl modificado, descrito por MORAES (1970), e a celulose pelo processo descrito por CRAMPTON' E MAYNARD (1938).

Os macronutrientes foram determinados através dos seguintes métodos analíticos:

a) cálcio, potássio e magnésio - segundo a técnica de espectrofotometria de absorção atômica (PERKIN-ELMER, 1966).

b) fósforo - pelo processo do vanadio-molibdato de amônio em extrato obtido por digestão da matéria sêca em ácidos nítrico e perclórico, segundo LOTT et alii (1956).

c) enxofre - pela determinação gravimétrica, através da precipitação do enxôfre pelo cloreto de bário, segundo TOTH et alii (1948). 
A digestibilidade "in vitro" da matéria sêca e da celulose foi determinada por um período de 48 horas, conforme o método descrito por CARVALHO (1967) e as modificações introduzidas por SILVEIRA (1970).

\section{RESULTADOS}

\section{Composição química-bromatológica}

A variação dos constituintes químico-bromatológicos através dos diversos estádios de desenvolvimento do capim Napier pode ser apreciada pelos elementos constantes do Quadro I, os quais confirmam, tal como foi observado na revisão da literatura referente ao assunto, que existe incompatibilidade entre os avançados estádios de maturidade e a adequada composição química-bromatológica.

QUADRO I - Efeito da maturidade sobre os teores dos constituintes químicobromatológicos na matéria sêca do capim Napier.

\begin{tabular}{ccccccc}
\hline \multirow{2}{*}{$\begin{array}{c}\text { Estádios } \\
\text { de } \\
\begin{array}{c}\text { maturida- } \\
\text { de em dias }\end{array}\end{array}$} & $\begin{array}{c}\text { Matéria } \\
\text { sêca \% }\end{array}$ & $\begin{array}{c}\text { Proteína } \\
\text { bruta }\end{array}$ & $\begin{array}{c}\text { Extrato } \\
\text { Etéreo }\end{array}$ & $\begin{array}{c}\text { Fibra } \\
\text { bruta }\end{array}$ & $\begin{array}{c}\text { Extrativos } \\
\text { não nitro- } \\
\text { genados }\end{array}$ & $\begin{array}{c}\text { Cinza } \\
\text { bruta }\end{array}$ \\
\cline { 3 - 7 } & 17,05 & 14,95 & 4,92 & 23,52 & 40,81 & 15,79 \\
45 & 20,15 & 6,95 & 3,83 & 28,64 & 47,20 & 13,36 \\
75 & 19,20 & 5,85 & 3,25 & 34,67 & 43,84 & 12,38 \\
105 & 25,58 & 3,97 & 3,01 & 36,82 & 48,34 & 7,84 \\
135 & 26,03 & 3,36 & 2,48 & 37,00 & 48,44 & 8,69 \\
165 & 34,08 & 2,76 & 2,25 & 38,52 & 49,35 & 7,10 \\
195 & 36,03 & 2,86 & 1,78 & 38,72 & 49,29 & 7,33 \\
225 & 32,05 & 2,31 & 1,64 & 38,35 & 49,35 & 8,33 \\
255 & 36,37 & 1,95 & 1,98 & 38,38 & 49,89 & 7,78 \\
285 & 36,39 & 2,04 & 2,07 & 38,40 & 50,37 & 7,10 \\
315 & & & & & & \\
\hline
\end{tabular}

Com efeito, os teores de proteina bruta e cinza bruta apresentaram-se de forma inversa, e os de matéria sêca e fibra bruta mostraram-se diretamente proporcionais à maturidade da planta, isto é, à medida que os cortes se distanciaram em relação à brota inicial. 
Os teores de matéria sêca foram significativamente influenciados pela maturidade da gramínea, elevando-se através dos diferentes tratamentos. Maiores produções de matéria sêca foram alcançadas nos meses de verão, com elevada precipitação pluviométrica e insolação, confirmando trabalhos anteriores.

A fibra bruta também teve seus teores elevados com o avançar do ciclo vegetativo do capim Napier, em consonância com trabalhos anteriores. Até o $4 .^{\circ}$ corte inclusive, efetuado aos 135 dias, os teores de fibra bruta foram inferiores aos de celulose, fato êste já comprovado para a determinação daquela primeira fração. A partir daquele corte, os teores de fibra bruta foram superiores aos de celulose, o que parece estar concórde com as observações de CRAMPTON e MAYNARD (1938). Os teores de fibra bruta dos últimos cinco cortes apresentaram pequenas diferenças, devido, ao que tudo indica, ao relativo desenvolvimento da planta, em consequência de um período de sêca bastante longo.

Por outro lado, a proteina bruta e a cinza bruta apresentaram teores decrescentes com o avançar do estádio de maturidade do capim Napier. Os maiores teores de proteina bruta foram encontrados nos três primeiros tratamentos, isto é, nas fases iniciais de brotação, por ocasião das maiores temperaturas e precipitações pluviométricas, ao passo que os teores menores corresponderam aos períodos de sêca e baixas temperaturas e à época de florescimento do capim, nos meses de março-abril, nas nossas condições, fatos estes concordantes com inúmeros trabalhos sôbre esta gramínea.

\section{Composição mineral}

A variação dos macronutrientes minerais através dos diversos estádios de desenvolvimento do capim Napier pode ser constatada pelos elementos constantes do Quadro II, dos quais se depreende que, em termos gerais, os teores de nitrogênio, fósforo, enxofre e potássio decresceram, os teores de magnésio mostraram tendência a se elevar, e os teores de cálcio apresentaram constante variação em relação aos estádios de maturidade da gramínea.

Os teores de nitrogênio, decrescentes através dos tratamentos, apresentaram maiores valores nos três primeiros cortes, quando a gramínea encontrava-se em franca brotação, confirmando trabalhos de CARO-COSTAS et alii (1960), HAAG et alii (1965) e HAAG et alii (1967).

Os teores de fósforo foram influenciados pelos tratamentos, decrescendo com a maturidade da planta. Os maiores teores corres- 
QUADRO II - Efeito da maturidade sobre os teores dos macronutrientes minerais na matéria sêca do capim Napier.

\begin{tabular}{ccccccc}
\hline $\begin{array}{c}\text { Estádios } \\
\text { de } \\
\text { maturida- } \\
\text { de em dias }\end{array}$ & Nitrogênio & Fósforo & Cálcio & Enxofre & Potássio & Magnésio \\
\cline { 2 - 7 } & 2,38 & 0,21 & 0,14 & 0,15 & 5,07 & 0,10 \\
75 & 1,10 & 0,12 & 0,16 & 0,08 & 3,71 & 0,10 \\
15 & 0,93 & 0,15 & 0,19 & 0,10 & 3,16 & 0,11 \\
135 & 0,63 & 0,05 & 0,42 & 0,07 & 1,60 & 0,15 \\
165 & 0,53 & 0,15 & 0,30 & 0,06 & 2,20 & 0,11 \\
195 & 0,43 & 0,03 & 0,18 & 0,06 & 1,19 & 0,16 \\
225 & 0,43 & 0,11 & 0,41 & 0,07 & 1,36 & 0,13 \\
255 & 0,36 & 0,04 & 0,20 & 0,09 & 1,67 & 0,11 \\
285 & 0,30 & 0,09 & 0,24 & 0,05 & 1,21 & 0,13 \\
315 & 0,32 & 0,04 & 0,15 & 0,07 & 1,25 & 0,15 \\
\hline
\end{tabular}

ponderam aos meses iniciais de brotação, e os mais baixos teores ocorreram nos meses de menor precipitação pluviométrica, parecendo confirmar trabalhos anteriores sobre a ocorrência de uma carência estacional de fósforo em animais vivendo sob pastoreio, como os de VILLARES e TEIXEIRA E SILVA (1956) e os de FRENCH e CHAPARRO (1960), ou ainda sôbre a deficiência do elemento em forrageiras naquela estação, como os de UNDERWOOD (1966) e os de ANDREASI et alii (1966-67). Os teores de fósforo encontrados até o terceiro corte pareceram estar em condições de atender as exigências nutricionais mínimas para bovinos em pastoreio.

A análise da variância correspondente não acusou diferença estatística significativa para os tratamentos referentes aos teores de cálcio, os quais não acompanharam a curva de crescimento do capim, deixando apenas transparecer tendência de elevação nos períodos correspondentes à seca anual. Isto se explica, já que na maioria das plantas o elemento encontra-se localizado nas fôlhas mais velhas (LINEBERRY e BURKHART, 1943, in MALAVOLTA et alii, 1967), e é relativamente imóvel nas plantas (MALAVOLTA et alii, 1967), ou quando estas já floresceram e se encontram maduras, confirmando trabalhos de WERNER (1971) e de ANDREASI et alii (1966-67). Os teores observados em todos os tratamentos encontram-se em condições de atender as exigências nutricionais dos animais em regime 
de pastoreio, o que foi também consignado por CARO-COSTAS et alii (1960), FRENCH e CHAPARRO (1960), GAVILLON' (1961), JARDIM et alii (1962), ARIAS e BUTTERWORTH (1965) e ANDREASI et alii (1966-67).

Os teores de enxofre e potássio decresceram e os de magnésio mostraram tendência a se elevar com a idade do capim Napier, com variações equivalentes àquelas registradas em outros trabalhos experimentais, com os de VICENTE-CHANDLER et alii (1959), FRANCH e CHAPARRO (1960), APPELMAN e DIRVEN (1962), HAAG et alii (1967) e GOMIDE et alii (1969a.). ANDREASI et alii (1966-67) determinaram que o potássio apresentou maiores índices na época das chuvas, o que parece estar de acôrdo com os dados apresentados neste trabalho. A curva do magnésio obtida parece confirmar citação de MALAVOLTA et alii (1967), isto é, de ser o magnésio elemento de fácil translocação no vegetal, e cujos sintomas de deficiência aparecem geralmente nas folhas mais velhas.

\section{Digestibilidade "in vitro"}

A variação dos teores de celulose e dos coeficientes de digestibilidade "in vitro" da matéria seca e da celulose, através dos estádios de desenvolvimento do capim Napier, consta do Quadro III.

QUADRO III - Efeito da maturidade sobre a digestibilidade "in vitro" da matéria sêca e da celulose do capim Napier.

\begin{tabular}{ccccccc}
\hline & \multicolumn{3}{c}{$\begin{array}{c}\text { Matéria sêca } \\
\%\end{array}$} & & \multicolumn{3}{c}{$\begin{array}{c}\text { Celulose } \\
\%\end{array}$} \\
$\begin{array}{c}\text { Estádios } \\
\text { de } \\
\begin{array}{c}\text { maturida- } \\
\text { de em dias }\end{array}\end{array}$ & M.S. & $\begin{array}{c}\text { Coef. } \\
\text { dig. } \\
\text { M.S. }\end{array}$ & $\begin{array}{c}\text { M.S. } \\
\text { dig. }\end{array}$ & Celulose & $\begin{array}{c}\text { Coef. } \\
\text { dig. } \\
\text { celulose }\end{array}$ & $\begin{array}{c}\text { Celulose } \\
\text { dig. }\end{array}$ \\
\cline { 2 - 7 } & & 71,64 & 12,22 & 25,59 & 78,10 & 19,98 \\
45 & 17,05 & 68,58 & 13,82 & 30,86 & 71,23 & 21,98 \\
75 & 20,15 & 59,25 & 11,38 & 35,63 & 63,38 & 22,57 \\
105 & 19,20 & 54,09 & 13,83 & 36,96 & 54,01 & 19,96 \\
135 & 25,58 & 53,47 & 13,90 & 36,95 & 51,65 & 19,11 \\
165 & 26,03 & 48,23 & 16,43 & 37,93 & 45,35 & 17,20 \\
195 & 34,08 & 47,35 & 17,05 & 37,24 & 43,28 & 16,11 \\
225 & 36,03 & 46,38 & 14,86 & 37,88 & 42,17 & 15,97 \\
255 & 32,05 & 45,05 & 16,38 & 37,88 & 39,02 & 14,78 \\
285 & 36,37 & 43,69 & 15,89 & 37,19 & 35,47 & 13,19 \\
315 & 36,39 & & & & & \\
\hline
\end{tabular}


Foi evidenciado o efeito dos tratamentos sobre a celulose, cujos teores se elevaram com a maturidade da forrageira, confirmando trabalhos levados a efeito por SILVA et alii (1965), VIEIRA e GOMIDE (1968), GOMIDE et alii (1969) e ANDRADE e GOMIDE (1970).

A maturidade influiu de forma negativa sobre a digestibilidade "in vitro" da matéria seca e da celulose, com coeficientes decrescentes através dos estádios de desenvolvimento do capim. A queda nos valores dos coeficientes de digestibilidade "in vitro" da matéria sêca e da celulose, em decorrência da maturidade, está associada à alteração do valor nutritivo da planta, conforme consignaram CRAMPTON e MAYNARD (1938), DEHORITY e JOHNSON (1961) e FRENCH (1956). A queda da digestibilidade "in vitro" da matéria seca foi estabelecida em trabalhos anteriores, como os de BURTON et alii (1963), MOWAT et alii (1965), SILVA et alii (1965) e ANDRADE e GOMIDE (1970), o mesmo ocorrendo com os coeficientes de digestibilidade "in vitro" da celulose, nos trabalhos de SILVA et alii (1965), ARROYO-AGUILÚ (1967), GOMIDE et alii (1969), ANDRADE e GOMIDE (1970) e SILVEIRA (1970).

\section{CONCLUSÕES}

Nas condições em que êste trabalho foi realizado, e tendo-se em conta os resultados obtidos, podem ser estabelecidas as seguintes conclusões :

1) Evidenciou-se a influência da maturidade do capim Napier (Pennisetum purpureum, Schum.) sôbre os principais constituintes químico-bromatológicos, fato êste já estabelecido para outras gramíneas. Assim, considerando o $10^{\circ} \mathrm{e}$ o $100^{\circ}$ cortes, num período de 270 dias, os teores de matéria sêca passaram de $17,05 \%$ para $36,39 \%$, os teores de proteína bruta na M.S. de $14,95 \%$ para $2,04 \%$, os teores de fibra bruta de $23,52 \%$ para $38,40 \%$, os teores de cinza bruta de $15,79 \%$ para $7,10 \%$, e os teores de celulose de $25,59 \%$ para $37,19 \%$.

2) Os maiores teores de matéria seca foram alcançados a partir do $2 .^{\circ}$ corte, época em que o capim Napier encontrava-se com altura normalmente preconizada para utilização.

3) A partir do $2 .^{\circ}$ corte, aos 75 dias, os teores de proteina bruta $(\mathrm{N} \times 6,25)$ não mais se encontraram dentro dos limites indicados para atender as exigências nutricionais mínimas dos bovinos em pastoreio.

4) Os maiores teores de fibra bruta foram alcançados a partir da época do florescimento da gramínea (março-abril), além da qual 
torna-se menos recomendada para o consumo animal, por influir negativamente sôbre a digestibilidade da mesma.

5) Os teores de nitrogênio, fósforo, enxofre e potássio, confirmando trabalhos anteriores referentes ao assunto, declinaram com o estádio de maturidade da forrageira.

6) Os teores de magnésio, confirmando observações anteriores, mostraram tendência a se elevar com o avançar da idade da forrageira, fato êste nem sempre esperado, já que o elemento é muito translocável na planta.

7) Os maiores teores de cálcio foram estabelecidos nos períodos correspondentes à estação seca do ano, ocasião em que a planta apresentava avançado estado de maturidade, o que confirma observações anteriores de ser o macronutriente encontrado em maiores proporções nas fôlhas e partes mais velhas da forrageira.

8) Os teores mais baixos de fósforo foram encontrados à partir da época seca do ano, o que também está concorde com trabalhos anteriores sobre a ocorrência de carência estacional daquele macronutriente, durante o inverno.

9) Os teores de cálcio, enxofre, potássio e magnésio estabelecidos no período experimental do capim Napier, aparentemente apresentaram-se em condições de atender às exigências nutricionais mínimas dos bovinos em pastoreio.

10) Os teores de fósforo encontrados até o $3 .^{\circ}$ corte, pareceram indicar que a forrageira se encontrava em condições de satisfazer as exigências mínimas para o atendimento animal.

11) Os macronutrientes que se apresentaram com os maiores teores foram, em ordem decrescente, o potássio, o nitrogênio, o cálcio, o magnésio, o fósforo e o enxofre.

12) Os teores de matéria seca, fibra bruta e celulose apresentaram correlações significativas e negativas com os teores de nitrogênio, fósforo, enxofre e potássio, e correlações positivas com os teores de magnésio.

13) Os teores de proteína bruta e cinza bruta apresentaram correlações significativas e positivas com os teores de nitrogênio, fósforo, enxofre e potássio, sendo que apenas os teores de cinza bruta correlacionaram-se de forma significativa e negativa com os de magnésio.

14) Constatou-se efeito negativo da maturidade sobre a digestibilidade do capim Napier. Assim, os coeficientes de digestibilidade "in vitro" da matéria seca passaram de $71,64 \%$, no $10^{\circ}$ corte com 45 
dias, para $43,69 \%$ no $10 .^{\circ}$ corte com 315 dias, com um decréscimo da ordem de $39,02 \%$, e os coeficientes de digestibilidade "in vitro" da celulose passaram de $78,10 \%$ para $35,47 \%$ no mesmo período de tempo, com um decréscimo da ordem de $54,59 \%$.

15) Estabeleceram-se correlações significativas, negativas e elevadas entre os coeficientes de digestibilidade "in vitro" da matéria seca e os teores da matéria seca $(r=-0,91)$, celulose $(r=-0,88)$ e fibra bruta $(r=-0,93)$ e correlações significativas com os teores de proteína bruta $(r=0,88)$ e de cinza bruta $(r=0,89)$.

16) Estabeleceram-se correlações significativas, negativas e elevadas entre os coeficientes de digestibilidade "in vitro" da celulose e os teores de matéria seca $(r=-0,93)$, celulose $(r=-0,85)$ e fibra bruta $(\mathrm{r}=-0,91)$, e correlações significativas com os teores de proteína bruta $(r=0,88)$ e de cinza bruta $(r=0,88)$.

17) Estabeleceu-se correlação significativa, positiva e elevada entre os coeficientes de digestibilidade "in vitro" da matéria seca e os de digestibilidade "in vitro" da celulose $(r=0,99)$.

18) Verificaram-se correlações significativas entre os coeficientes de digestibilidade "in vitro" da matéria seca e os teores de nitrogênio, fósforo, enxofre e potássio $(\mathrm{r}=0,88, \mathrm{r}=0,66, \mathrm{r}=0,66 \mathrm{e}$ $r=0,90$, respectivamente), e correlações significativas e negativas com os teores de magnêsio $(r=-0,43)$.

19) Verificaram-se correlações significativas entre os coeficientes de digestibilidade "in vitro" da celulose e os teores de nitrogênio, fósforo, enxofre e potássio $(r=0,88, r=0,68, r=0,68$ e $r=0,89$, respectivamente), e correlações significativas e negativas com os teores de magnésio $(r=-0,41)$.

\section{SUMMARY}

SEASONAL VARIATION IN THE CHEMICAL COMPOSITION, MAJOR MINERAL NUTRIENTS AND "IN VITRO" DIGESTIBILITY OF NAPIER GRASS (Pennisetum purpureum, Schum).

This paper deals with an experimental work carried out in order to estimate the chemical composition, the major minerals content and the "in vitro" dry matter and cellulose digestibility coefficients of napier grass (Pennisetum purpureum, Schum), during the year. Random blocks, including $15 \mathrm{~m}^{2}$ plots with 10 treatments (cuttings) and 3 replications, was the experimental design used.

The forage was harvested at 45, 75, 105, 135, 165, 195, 225, 255, 285 and 315 days of vegetative growth, and the samples collected in previously established dates, at the same day hour. 
It was observed a maturity effect on the chemical composition of napier grass. Higher dry matter contents were observed after the second cutting, which is considered the best stage of vegetative growth in relation to heigth of forage, for harvesting. However, after 75 days the crude protein contents were not enough to meet the minimum nutrient requirements of cattle under grazing management. The highest crude fiber contents were observed in the flowering stage.

It was noted that nitrogen, phosphorus, sulfur and potassium concentrations became lower as maturity was reached. In the other hand, magnesium content showed a consistent tendency to increase in the latter cuttings.

The highest calcium concentration was observed during the dry season of the year, when the forage was in the advanced stage of maturity. In relation to phosphorus, the lowest concentrations were also found during the dry season, and this fact confirms several previous observations on the seasonal defficiency of phosphorus in forage. Calcium, sulfur, potassium and magnesium contents could be considered enough to cover the nutrients requirements of cattle. However, as far as phosphorus is concerned, only during the first phase of vegetative growth (third cutting) the grass would have enough phosphorus to meet the minimum requirements of cattle.

Dry matter, crude fiber and cellulose contents showed significative and negative correlations to nitrogen, phosphorus, sulfur and potassium concentrations, but to the magnesium content, the correlation was positive. On the other hand, crude protein and ash contents presented significative and positive correlations to nitrogen, phosphorus, sulfur and potassium contents, exception to magnesium content showed significative and negative correlation to ash.

It was observed a negative effect of maturity on the digestibility of napier grass. "In vitro" dry matter digestibility coefficients declined from $71,64 \%$ in the first cutting at 45 days to $43,69 \%$ in the tenth cutting at 315 days, and in relation to cellulose the reduction was $78,10 \%$ to $35,47 \%$, respectively.

"In vitro" dry matter digestibility coefficients were negative and highly correlated to dry matter $(r=-0,91)$, cellulose $(r=-0,88)$ and crude fiber $(r=-0,93)$ contents, and positively correlated to crude protein $(r=0,88)$ and ash $(r=0,89)$ contents. In the same way, it was noted a negative and high correlation between "in vitro" cellulose digestibility and dry matter $(r=-0,93)$, cellulose $(r=-0,85)$, and crude fiber $(r=-0,91)$, and significative correlation to crude protein $(r=0,88)$ and ash $(r=0,88)$ contents. A positive and high correlation 
was observed between "in vitro" digestibility coefficients of cellulose and dry matter $(r=0,99)$.

Significative correlation coefficients were found between "in vitro" dry matter digestibility and nitrogen $(\mathrm{r}=0,88)$, phosphorus $(r=0,66)$, sulfur $(r=0,66)$ and potassium $(r=0,90)$ contents, but in relation to magnesium it was observed a negative correlation $(\mathrm{r}=-0,43)$. The same situation was observed as "in vitro" cellulose digestibility is concerned, that is : nitrogen $(r=0,88)$, phosphorus $(r=0,68)$, sulfur $(r=0,68)$, potassium $(r=0,89)$ and magnesium $(r=-0,41)$.

\section{LITERATURA CITADA}

ANDRADE, I. F. e J. A. GOMIDE - 1970. Curva de crescimento e valor nutritivo de capim elefante A-146 Taiwan. VII Reunião Anual da Sociedade Brasileira de Zootecnia, Piracicaba. (Mimeografado).

ANDREASI, F., J. S. M. VEIGA, C. X. MENDONÇA JUNIOR, F. PRADA e R. C. BARNABE. - 1966-1967. Levantamento dos elementos minerais em plantas forrageiras de áreas delimitadas do estado de São Paulo. I - Cálcio, Fósforo e Magnésio. Rev. da Faculdade de Medicina Veterinária da Universidade de São Paulo 7(3):583-604.

ANDREASI, F., C. X. MENDONÇA JUNIOR, J. S. M. VEIGA, F. PRADA e N. MASOTTI - 1966-1967. Levantamento dos elementos minerais em plantas forrageiras de áreas delimitadas do estado de São Paulo. II - Sódio e Potássio. Rev. da Faculdade de Medicina Veterinária da Universidade de São Paulo, 7(3):605-614.

A.O.A.C. - 1965. Official Methods of Analysis. Association of Official Agricultural Chemists. Tenth edition. Washington, D. C.

APPELMAN, H. e J. G. P. DIRVEN - 1962. The influence of the cutting interval on the chemical composition of various grasses. Surinaam. Landb, 10(3):95-102. English summary.

ARIAS, P. J. e M. BUTTERWORTH - 1965. Crescimiento del pasto elefante. Anais do IX Congresso Internacional de Pastagens, D. P. A., São Paulo, $1: 407-412$.

ARROYO-AGUILÚ, J. A. 1967. Estimation of digestibility from "in vitro" rumen fermentation data in some forages of Puerto Rico. J. Agric. Univ. Puerto Rico, 51(2):133-139.

BURTON, G. W., J. E. JACKSON and R. H. HART - 1963. Effects of cutting frequency and nitrogen on yield, "in vitro" digestibility, and protein, fiber and carotene content of Coastal Bermudagrass. Agronomy, J., 55(5):500502 .

CARO-COSTAS, R., J. VICENTE-CHANDLER e J. FIGARELLA - 1960. The yields and composition of five grasses growing in the humid mountains of Puerto Rico, as affected by nitrogen fertilization, season, and harvest procedures. J. Agric. Univ. Puerto Rico, 44(3):107-120.

CARVALHO, M. M. - 1967. A técnica do rumen artificial na estimativa de digestibilidade aparente de forrageiras tropicais. Tese de M. S., Universidade Rural do Estado de Minas Gerais, Viçosa. 
CRAMPTON, E. W. and L. A. MAYNARD. - 1938. The relation of cellulose and lignin content to the nutritive value of animal feeds. J. Nutrition, 15(4):383-395.

DEHORITY, B. A. and R. R. JOHNSON - 1961. Effect of particle size upon the "in vitro" cellulose digestibility of forages by rumen bacteria. J. Dairy Sci., 44(12):2242-2249.

FRENCH, M. H. - 1956. The nutritive value of East African hay. Empire J. Exp. Agric., 24(93):53-60.

FRENCH, M. H. e L. M. CHAPARRO - 1960. Contribución al estudio de la composición química de los pastos en Venezuela durante la estación seca. Agronomia Tropical, 10(2):57-69.

GAVILLON, O. - 1961. Levantamento da composição mineral das pastagens do Rio Grande do Sul. II. Os minerais maiores e a composição imediata. A Granja, Porto Alegre, 18(175):34-36.

GOMIDE, J. A., C. H. NOLLER, G. O. MOTT, J. H. CONRAD e D. L. HILL, 1969. Effect of plant age and nitrogen fertilization on the chemical composition and "in vitro" cellulose digestibility of tropical grasses. Agronomy J., 61(1):116-120.

GOMIDE, J. A., C. H. NOLLER, G. O. MOTT, J. H. CONRAD e D. L. HILL 1969a. Mineral composition of six tropical grasses as influenced by plant age and nitrogen fertilization. Agronomy J., 61(1):120-123.

HAAG, H. P., F. A. F. MELLO, M. O. C. BRASIL SOBRINHO, A. COBRA NETTO, R. G. ANDRADE e R. G. COELHO - 1965. Estudos sobre a nutrição mineral do Pennisetum purpureum, Schum, var. Napier cultivado em solução nutritiva. Anais do IX Congresso Internacional de Pastagens, D. P. A., São Paulo, 1:691-695.

HAAG, H. P., M. L. V. BOSE e R. G. ANDRADE - 1967. Absorção dos macronutrientes pelos capins Colonião, Gordura, Jaraguá, Napier e Pangola. Anais da E.S.A. "Luiz de Queiróz", Piracicaba, 24:177-188.

JARDIM, W. R., A. M. PEIXOTO e C. L. MORAES - 1962. Observações sobre deficiências minerais na nutrição dos bovinos na região do Brasil Central. Boletim Técnico Científico n.o 13. E.S.A. "Luiz de Queiróz", Piracicaba.

LOTT, W. L., J. P. NERY, J. R. GALLO e J. C. MEDCALF - 1956. A técnica de análise foliar aplicada ao cafeeiro. Instituto Agronômico, Campinas, Boletim n. ${ }^{\circ} 79$.

MALAVOlta, E., H. P. HAAG, F. A. F. de MELLO e M. O. C. BRASIL SOBRINHO - 1967. Nutrição mineral de algumas culturas tropicais. Editôra da Universidade de São Paulo. São Paulo.

MORAES, C. L. de - 1970. Análise de Forragem. C.P.G. de Nutrição Animal e Pastagens, E. S. A. "Luiz de Queiróz", Piracicaba. (Mimeografado).

MOWAT, D. N., R. S. FULKERSON, W. E. TOSSELL e J. E. WINCH. 1965. Digestibilidade "in vitro" da matéria seca de várias espécies e variedades de plantas assim como de suas partes com o aumento da maturidade. Anais do IX Congresso Internacional de Pastagens, D.P.A., São Paulo, 1:801-806.

PERKIN-ELMER - 1966. Analytical methods for atomic absorption spectrophotometry. Connecticut, Perkin-Elmer Corp. 
SILVA, D. J. DA, J. H. CONRAD e J. CAMPOS - 1965. Da digestibilidade "in vitro" de algumas forrageiras tropicais. Anais do IX Congresso Internacional de Pastagens. D.P.A., São Paulo, 1:895-897.

SILVEIRA, A. C. - 1970. Efeito da maturidade da planta e diferentes tratamentos sôbre a digestibilidade "in vitro" de silagens de capim elefante, variedade Napier (Pennisetum purpureum, Schum.), Tese de M.S., E.S.A. "Luiz de Queiróz", Universidade de São Paulo.

TOTH, S. J., A. L. PRINCE, A. WALLACE e D. S. MIKKELSEN - 1948. Rapid quantitative determination of eight mineral elements in plant tissues by a sistematic procedure involving use of a flame photometer. Soil Sci., $66(6): 459-466$.

UNDERWOOD, E. J. - 1966. The mineral nutrition of livestock - Food and Agriculture Organization of the United Nations and Commonwealth Agricultural Bureaux. The Central Press (Aberdeen) Ltd.

VICENTE-CHANDLER, J., S. SILVA e J. FIGARELLA - 1959. The effect of fertilization and frequency of cutting on the yield and composition of three tropical grasses. Agronomy J., 51(4):202-206.

VIEIRA, L. M. e J. A. GOMIDE. - 1968. Composição química e produção forrageira de três variedades de capim elefante. Rev. Ceres, 15(86):245-260.

VILLARES, J. B. e H. M. TEIXEIRA E SILVA - 1956. Contribuição para o estudo das carências minerais em bovinos no Estado de São Paulo. I Levantamento do índice de fósforo no sangue de vacas Guzerá na Fazenda Experimental de Criação de Sertãozinho. Boletim da Indústria Animal, São Paulo, 15 ( N. ${ }^{\circ}$ único):5-22.

WERNER, J. C. - 1971. Estudos sôbre a nutrição mineral de alguns capins tropicais. Tese de doutoramento. E.S.A. "Luiz de Queiróz", Universidade de São Paulo, Piracicaba. 
